\begin{abstract}
مقاله يخووهشى
مجله دانشگاه علوم يزشكى رفسنجان

دوره 19، تير MqM

بررسى همبستكى بين دامنه حر كتى مفاصل با زمان انواع دويدن در دختران دونده نخب نخبه نوجوان

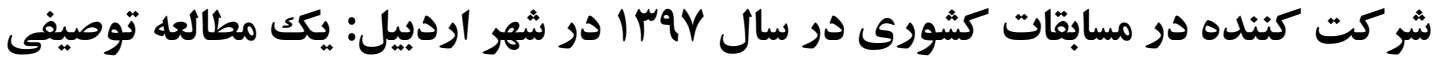

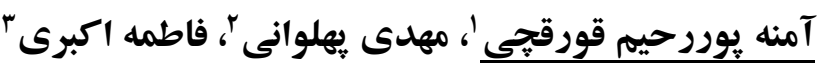

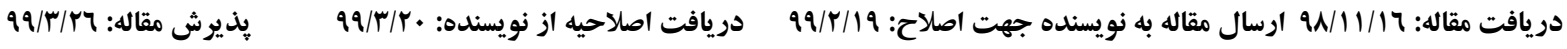
جـكيده

زمينه و هدف: رابطه دامنه حركتى مفاصل با زمان دويدن براى موفقيت ورزشى مههم است. هدف اين مطالعه تعيين

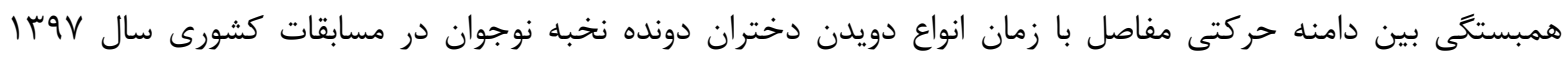
اردبيل بود.

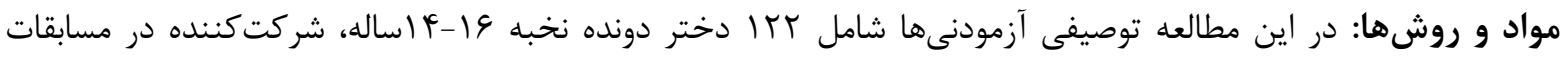

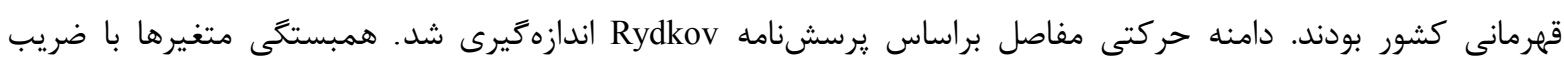
همبستخى Pearson ارزيابى شد.

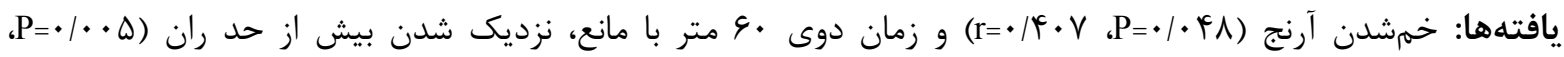

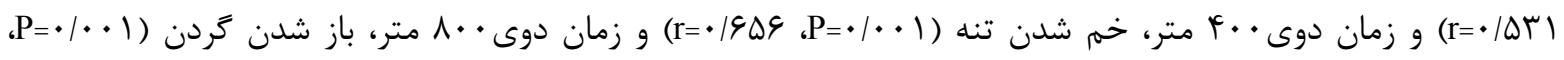

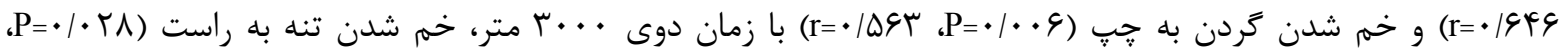
ل

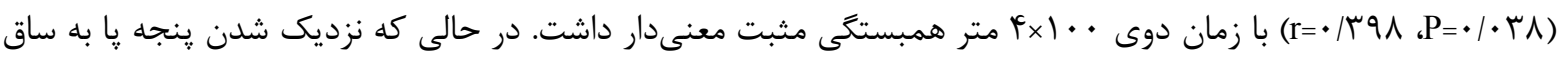

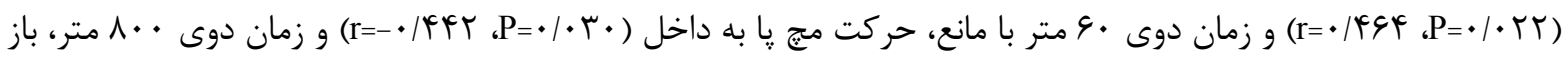

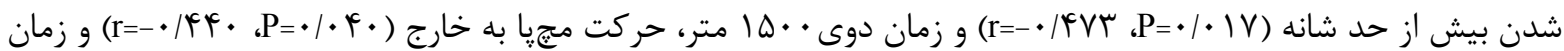
دوى ... م متر همبستخى منفى معنى دار داشت.

نتيجهَيرى: به نظر مىرسد بين دامنه حركتى مفاصل و زمان انواع دويدن دختران دونده نخبه همبستكى معنى دار وجود دارد. لذا، به مربيان ييشنهاد مىشود هنگام انتخاب دختران دونده نوجوان به نتايج تحقيق حاضر توجه كنند تا موفقيت بيش ترى در رسيدن به اوج عملكرد ورزشى كسب نمايند. روازههاى كليدى: ويزَّى هاى بيومكانيكى، زمان دويدن، دختران، دونده نخبه، اردبيل
\end{abstract}

1- استاديار فيزيولوزى ورزشى كروه تربيت بدنى و علوم ورزشى، دانشكده علوم تربيتى و روانشناسى، دانشگاه محقق اردبيلى، اردبيل، ايران

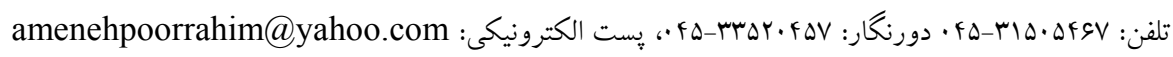

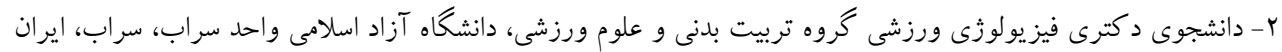

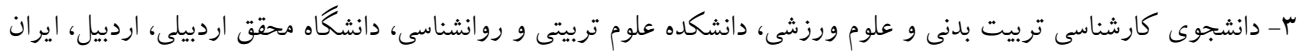


دو و ميدانى از يك الكَوى استعداديابى استفاده مىشود

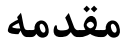

[1][. در كشور ما، معيار علمى نيز براى گزينش افراد

مستعد جهت جذب به دو و ميدانى وجود ندارد و اين امر

تنها از طريق روش سنتى جشنوارههاى مناسبتى و موسمى

و نيز مسابقات داخلى انجام مى گيرد [ • [1]. دختران و وِران

از تمرين و رقابت بهره مىبرند و قادرند عملكردهاى دويدن و

يريدن خود را در طى دوران كودكى تا بعد از بلوغ بهبود

بخشند. دختران و پسران معمولاً بهترين عملكرد دويدن و

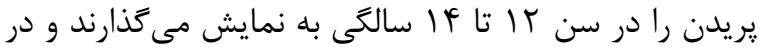

پِران تا سن 19 سالكى و در دختران تا سن 11 سالكى به

$$
\text { حالت يكنواخت مىرسد [1 [| || }
$$

شاخصهاى جسمانى و بيومكانيكى مىتوانند در شناسايى

افراد مستعد سودمند باشند به ويزه اينكه شاخصهاى

קيكرى تحت تأثير عوامل زنتيكى قرار دارند و از تمرين و

تغذيه تأثير اندكى مىيذيرند [ها]. تجزيه و تحليل عملكرد

ورزشكاران در مسابقات بزرى بينالمللى و بازىهاى

المييك نشان مىدهد موفقيت يك ورزش كار از تركيب

توانمندى ورزشى، ساختار و ويزگىهاى جسمانى و بدنى و

دامنه حركتى مفاصل تأثير مىيذيرد [V-|V| [|]. سرعت

دويدن ورزشكار براساس طول و تواتر كامها تعيين مىشود

[.1V-1] و سرعت كام بردارى مطلوب به مكانيكهاى

دويدن، تكنيك هماهنكَى ورزش كار و همجنين عواملى جون

اندازههاى آنترويومتريكى، بيومكانيكى و تركيب بدن و

عملكرد ورزشى در نوجوانان نيز تحت تأثير شاخصهاى

مختلف از جمله ويزگىهاى ييكرسنجى، فيزيولوزيكى، بيومكانيكى و دامنه حركتى مفاصل قرار دارد [ـ-1] كه بايد اين شاخصها را جهت پيشبينى عملكرد ورزشكاران نوجوان در نظر گرفت [ץ]. دو و ميدانى رشته پايه و مادر ورزشها مىباشد و رشد آن در هر كشورى به توسعه ديخر رشتههاى ورزشى منجر مىشود. همجنين از نظر قهرمانى در مسابقات رسمى مدالهاى متعددى را نصيب كشورها كند [4-4]. با توجه به تنوع و فراگير بودن رشته دو و ميدانى كه بيش از FV ر شته قهرمانى مجزا (F ماده آقايان و r r ماده براى خانمها) برنامه المريك دارد [V]، هر كشورى با برنامه ريزى و نكاهى عميق به اين رشته مىتواند مدالهاى زيادى را

$$
\text { نصيب خود گرداند [A- [1]. }
$$

بسيارى از كشورها در تلاش هستند تا با توسعه ساختار نظاممند خود به شناسايى ورزش كاران مستعد بيردازند تا از اين طريق امكان توسعه و ترويج يك رشته ورزشى را فراهم سازند [.1-9]. طى ساليان سال با افزايش حساسيت مسابقات دو و ميدانى در سطوح مختلف و بهبود كيفيت همهجانبه عملكرد ورزش كاران به خصوص در ردههاى يايه شناسايى به موقع استعدادهاى ورزشى در نوآموزان به نحو روزافزونى اهميت يافته است [Wadavi و و Zarifi نشان دادند كه در دو و ميدانى ايران الخوى استعداديابى مشخص و منسجمى وجود ندارد، ولى در بسيارى از كشورهاى صاحب 
مفاصل با زمان انواع دويدن در دختران دونده نخبه نوجوان شركت كننده در مسابقات كشورى در سال Vqrا شهر

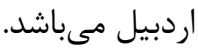

\section{مواد و روشها - - ماد}

اين مطالعه از نوع توصيفى مىباشد. r ا ا دختر نوجوان نخبه دو و ميدانى كار ع-4| ساله، شركت كننده در مسابقات قهرمانى كشور در سال VI I در شهر اردبيل، آزمودنىهاى تحقيق حاضر بودند كه مقامهاى برتر را در مسابقات قهرمانى استانهاى خود به دست آورده و به مسابقات كشورى راه يافته و يرسشنامه اطلاعات فردى را تكميل كردند. فرم رضايتنامه توسط والدين آزمودنىها تكميل و امضاء شد. جَكونكى اجراى تحقيق و گرسشنامه هاى اطلاعات فردى به همراه يرسشنامهاى اندازهيرى يارمتراها به آزمودنى ها و والدين آنها تحويل داده شد. كليه يرسشنامهها در حين مراحل اندازهيرى پارامترهاى تحقيق توسط محققين تكميل و جمعآورى شد. ويزگىهاى دموكرافيك آزمودنىها شامل سن، وزن و قد نيز همزمان با اندازهيرى دامنه حركتى مفاصل اندازميرى شد. با توجه به اين كه در جلسه توجيهى هدف از تحقيق براى كليه سريرستان، مربيان، اولياء و ورزشكاران توضيح داده شد، آنها خود براى شركت در اين تحقيق اشتياق داشتند. كليه اصول اخلاقى كار بر اساس بيانيه هلسينكى رعايت شد. يزوهش حاضر در كميته اخلاق دانشكاه علوم يزشكى اردبيل (IR.ARUMS.REC.1398.185)
ارتباط بين توانايىهاى زيست حركتى بستكى دارد [19. [IV برخى محققان نشان دادند كه بين دامنه حركتى مفاصل و عملكرد دويدن رابطه معنىدارى وجود دارد، در حالى كه برخى ديگر از محققان نشان دادند كه بين دامنه حركتى مفاصل و عملكرد دويدن رابطه معنىدارى وجود ندارد [بr-

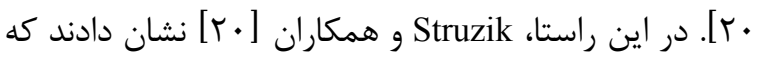
بين دامنه حركتى مفاصل و زمان دوى •ب متر سرعت در رابطه مستقيمى و معنى دارى وجود دارد. Hewlett [ (اr] نشان دادند كه بين خم شدن ران و زمان عملكرد رابطه منفى معنى دار وجود دارد. همهجنين، بين خم شدن و باز شدن تنه و سرعت دويدن رابطه معنىدار وجود دارد. در مقابل، Folland عمل كرد دويدن رابطه معنىدارى وجود ندارد. Makaruk و همكارش نشان دادند كه ارتباط معنىدارى بين دامنه حركتى مفاصل و زمان دويدن وجود ندارد [سr]. با توجه به كاهش سن قهرمانى در ورزش و دستيابى به اوج عملكرد، تعيين فاكتورهاى بهبود دهنده عملكرد با اهميت است. از طرفى، مطالعات انجام شده در زمينه بررسى عملكرد دختران دو و ميدانى كار نوجوان نخبه بسيار محدود

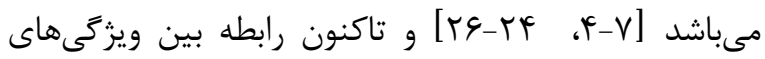
دامنه حركتى مفاصل با زمان دويدن در دوهاى مختلف در دختران نخبه نوجوان مورد بررسى قرار نكَرفته است. بنابراين هدف تحقيق حاضر تعيين همبستگى بين دامنه حركتى 
تيمها در اندازهيرىها حذف شدند. بنابراين، گِارامترهاى

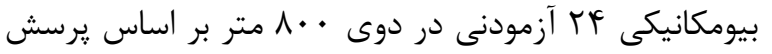
نامه Rydkov اندازهگيرى شد. تعداد شركت كنندگان در دوى · • • ا متر، TV نفر بودند كه T نفر به دليل عدم همكارى تيمها در اندازهگيرىها حذف شدند. بنابراين، يارامترهاى بيومكانيكى له آزمودنى در دوى · • ل1 متر بر اساس :رسشنامه Rydkov اندازهگيرى شد. تعداد شركت كنندگان در دوى · .. متر، له نفر بودند كه ب نفر به دليل عدم همكارى تيمها در اندازهخيرىها حذف شدند.

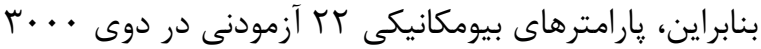
متر بر اساس يرسشنامه Rydkov اندازهگيرى شد. تعداد شركت كنند نفر به دليل عدم همكارى تيمها در اندازهخيرىها حذف شدند. بنابراين، يارامترهاى بيومكانيكى ^ر آزمودنى در دوى

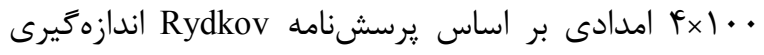

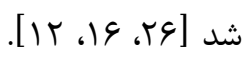

يارامترهاى بيومكانيكى شامل دامنه حركتى مفاصل گَردن در جهار جهت (خمى شدن به جلو، باز شدن به عقب، خم شدن به راست و خمم شدن به جֶ)، تنه در جهار جهت (خم شدن و باز شدن بيش از حد، خمشدن به راست و خم شدن به جֶ)، شانه در سه جهت (خمم شدن، باز شدن بيش از حد و دور شدن)، آرنج در دو جهت (خم شدن و باز شدن بيش از حد)، مج دست در جههار جهت (انحراف به طرف زند بالايى و انحراف به طرف زند يايينى، خم شدن و باز شدن)،
آزمودنىهاى تحقيق حاضر از طريق سرشمارى در زمان يذيرش تيمها و روز قبل از مسابقات در محل جلسه كميته فنى به دست آمدند و شامل كليه دختران نوجوان شركت كننده در مسابقات كشورى دو و ميدانى در مواد مختلف بودند كه در مواد مختلف در استانهاى خود مقامهاى اول تا سوم را به دست آورده بودند و با توجه به سهميه هر استان به مسابقات كشورى راه يافته بودند. تعداد افراد ذكر شده در هر ماده نيز تعداد شركت كنندگان در هر ماده بود كه از قبل شكل گَرفته بودند. تعداد افراد در هر گروه در مقالات نيز از

ها نفر تا • س نفر بودند كه ذكر شدهاند [عr، • ז، rا]. تعداد شركت كنندگان در دوى سرعت • • متر، • نفر بودند كه F نفر به دليل عدم همكارى تيمها در اندازهخيرىها حذف شدند. بنابراين، پارامترهاى بيومكانيكى צr آزمودنى در دوى • ع متر بر اساس يرسشنامه Rydkov اندازهيرى شد. تعداد شركت كنند وץ نفر بودند كه ه نفر به دليل عدم همكارى تيمها در اندازهزيرىها حذف شدند. بنابراين، يارامترهاى بيومكانيكى FF آزمودنى در دوى •و متر با مانع بر اساس يرسشنامه اندازهگيرى شد. تعداد شركت كنندگان در دوى Rydkov

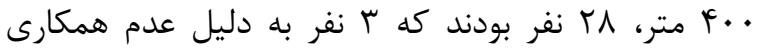
تيمها در اندازهگيرىها حذف شدند. بنابراين، يارامترهاى

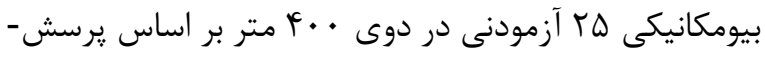
نامه Rydkov اندازهگيرى شد. تعداد شركت كنندگان در دوى • •1 متر، צr نفر بودند كه † نفر به دليل عدم همكارى 
جرخش مفصل مج پا به داخل ارائه شده است (شكل I الف

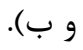

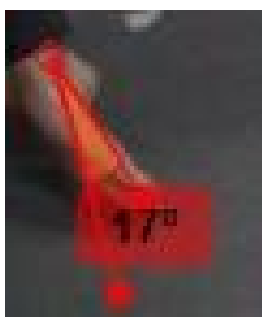

ب

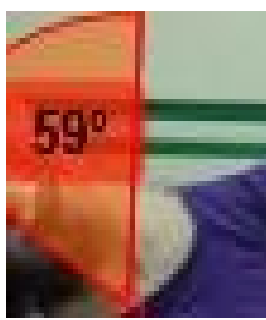

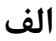

ران در جهار جهت (خهم شدن، باز شدن بيش از حد، دور شدن و نزديك شدن بيش از حد)، زانو در يك جهت (خم شدن)، مج ֶا در دو جهت (دور شدن קنجه پا از ساق و نزديك شدن ينجه پا به ساق) و مفصل تحت قايى در دو جهت (حركت ڤا به داخل و حركت پا به خارج) اندازهيرى

شد. همرجنين علامت كذارىهاى آناتوميكى براى برآورد

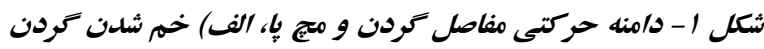
به راست و ب) جرخش مغصل مجه پإ به داخل براى تجزيه و تحليل آمارى دادهها از نرم افزار آمارى SPSS توزيع فراوانى دادهها از آزمون Shapiro-Wilk، و براى بررسى رابطه بين دامنه حركتى مفاصل و عملكرد (زمان) دويدن از ضريب همبستخى Pearson استفاده شد. سطح معنى دارى در آزمونها هـ • • در نظر كرفته شد. نتايج

آزمون Shapiro-Wilk نشان داد كه تمامى دادهها از

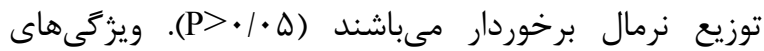
دموكرافيك آزمودنىهاى تحقيق شامل سن، قد، وزن، سابقه دويدن، زمان دويدن و شاخص توده بدنى در جدول ا نشان داده شده است. جدول ا نشان مىدهد كه بين ويزگىهاى دموكرافيك آزمودنىها و زمان انواع دويدن، تفاوت آمارى

$$
\text { معنى دارى وجود ندارد (ه •/P>) (P). }
$$
دقيقتر يارامترهاى بيومكانيكى انجام شد. براى اندازهيرى : يارامترهاى بيومكانيكى، آزمودنىها در وضعيت آناتوميكى ايستاده و حر كات مربوط به دامنه حركتى مفاصل را اجرا كردند و زواياى ذكر شده با استفاده از گونيامتر (مدل Spinit ساخت شركت Kapro كشور تايوان تحت ليسانس آمريكا) اندازهيرى شد. براى اندازهيرى دقيق از دوربين ديجيتالى (مدل Eos-40Dcanun ساخت شركت Canon (ساخت شركت Kinovea كشور آمريكا Kinovea.Setup) استفاده شد. كليه اندازهيرىها دو بار انجام شد و سيس ميانگين گرفته شد [عץ]. تمامى اندازهيرىها از ساعت 1 تا rا ظهر در محل سالن تختى شهر اردبيل انجام شد. اندازه گَيرى شاخصهاى بيومكانيكى توسط نويسندكان مقاله كه در اين زمينه آموزشهاى كافى و مناسب ديدهاند، انجام شده است. براى نمونه دو تصوير الف و ب در شكل 1 جهت اندازهيرى دامنه حركتى انحراف مفصل گردن در حركت خم شدن گردن به راست و در مفصل مج پا در حركت 


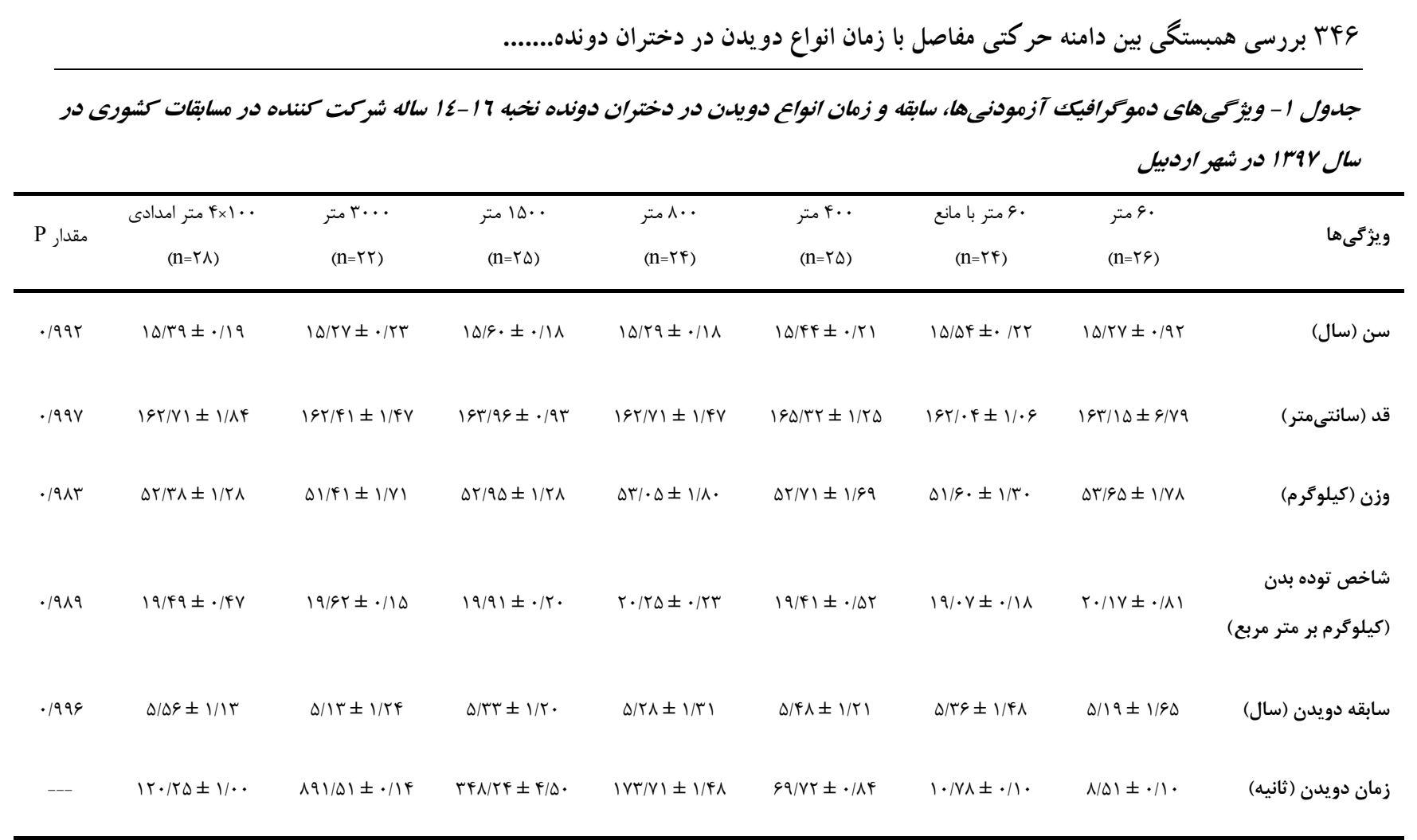

\section{دادههاى جدول به صورت "انحراف معيار 土 ميانَكين" كزارش شده /ست.}

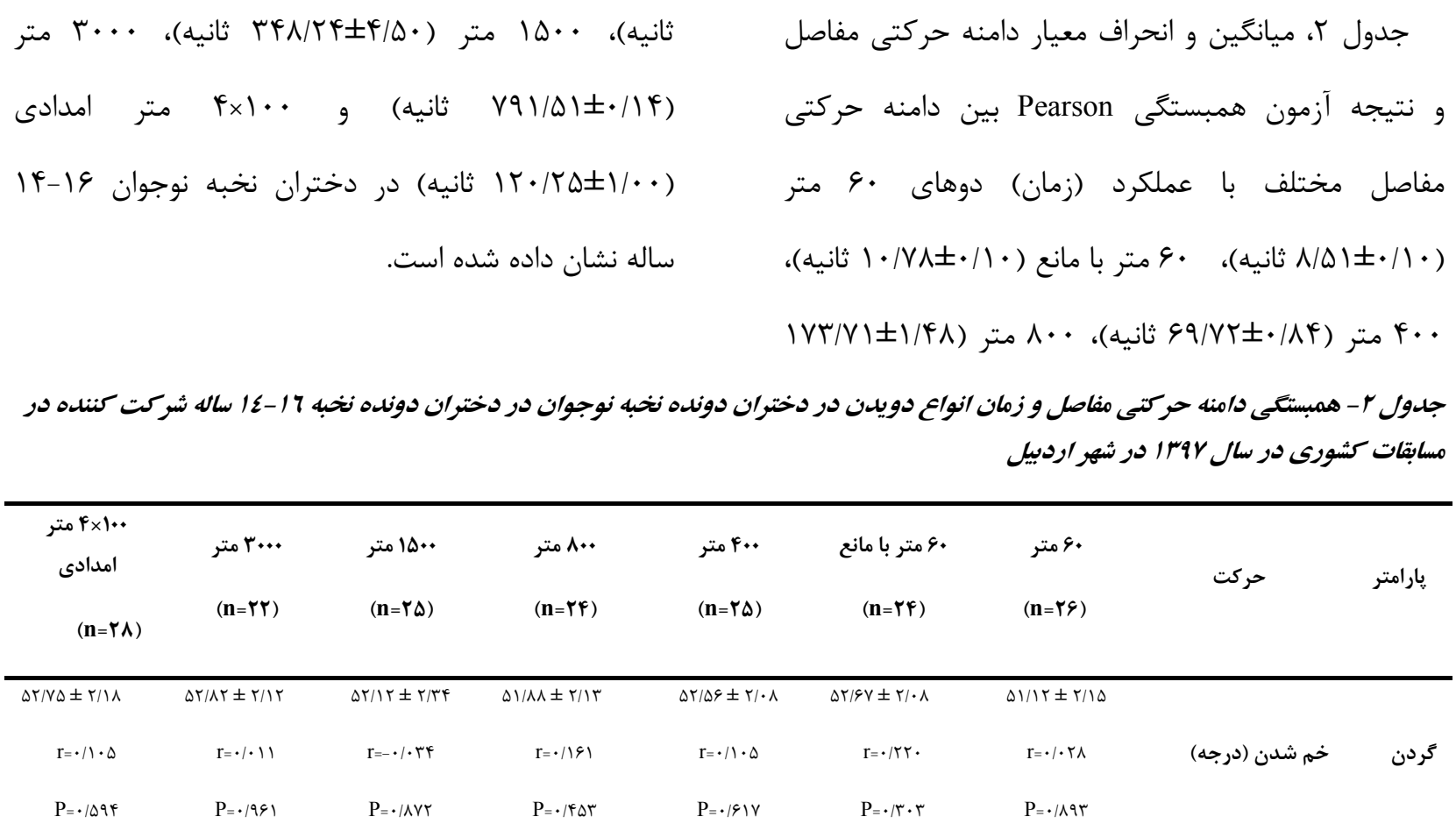




\begin{tabular}{|c|c|c|c|c|c|c|c|c|}
\hline$<\varepsilon / 9 \varphi \pm r / \cdot 1$ & $\Delta r / q \Delta \pm r / q \Lambda$ & $r V / 19 \pm r / r r$ & $\Delta \cdot / \Lambda \Lambda \pm r / 99$ & $\Delta \cdot / F \Lambda \pm r / V F$ & $r q / \cdot q \pm r / \Delta q$ & $\Delta \cdot / r V \pm r / r)$ & & \\
\hline $\mathrm{r}=\cdot \cdot \cdot \cdot \Delta \Lambda$ & $\mathrm{r}=.1949$ & $\mathrm{r}=-\cdot / / r$. & $r=-\cdot / 190$ & $r=\cdot / 1 \cdot r$ & $\mathrm{r}=-\cdot / 19 \mathrm{r}$ & $\mathrm{r}=-\cdot / r \| 1$ & باز شدن (درجه) & \\
\hline $\mathrm{P}=\cdot / V 99$ & $\mathrm{P}=\cdot \cdot \cdot \cdot 1$ & $\mathrm{P}=\cdot / \Delta r f$ & $\mathrm{P}=\cdot|r q|$ & $\mathrm{P}=\cdot / 9 \pi r$ & $\mathrm{P}=\cdot / \kappa \Delta$. & $\mathrm{P}=\cdot / / T r$ & & \\
\hline $4 \cdot 194 \pm 1 / v \Delta$ & $f \cdot / \cdot . \pm 1 / q \gamma$ & $r \cdot / \Lambda \cdot \pm 1 / 9 r$ & $F I / F r \pm 1 / M \Lambda$ & $\kappa r / . . \pm 1 / \Lambda \Delta$ & $\varphi \cdot / r \Delta \pm 1 / \Lambda \varphi$ & $r \cdot / \Delta \Lambda \pm 1 / 9 r$ & & \\
\hline $\mathrm{r}=\cdot / r \Lambda \Lambda$ & $\mathrm{r}=\cdot / \pi \Delta \Delta$ & $\mathrm{r}=-\cdot / \pi \mathrm{r} \mid$ & $\mathrm{r}=-\cdot / \mathrm{r} \cdot 9$ & $\mathrm{r}=\cdot / / F T$ & $\mathrm{r}=-. / \pi 99$ & $\mathrm{r}=\cdot \cdot \cdot \cdot \mathrm{vr}$ & خم شدن به راست & \\
\hline $\mathrm{P}=\cdot / / r \Lambda$ & $\mathrm{P}=\cdot / 1 \cdot \Delta$ & $\mathrm{P}=\cdot / r \Lambda \Lambda$ & $\mathrm{P}=\cdot / / 4 t$ & $\mathrm{P}=\cdot / 499$ & $\mathrm{P}=\cdot / 1 \Delta \varphi$ & $\mathrm{P}=\cdot / V Y \Lambda$ & & \\
\hline$r N / \uparrow \varepsilon \pm 1 / \cdot V$ & $r q / \gamma v \pm 1 / 1$. & $r N / r \cdot \pm 1 / 1 \Delta$ & $\uparrow \cdot / . . \pm 1 / / \Lambda$ & $r q / f 4 \pm 1 / r \Lambda$ & $r q / / \gamma \pm 1 / \cdot \Delta$ & $r q / / r \pm 1 / / f$ & & \\
\hline $\mathrm{r}=\cdot \cdot \cdot \cdot \Delta \Lambda$ & $\mathrm{r}=\cdot / \Delta q \mu$ & $\mathrm{r}=\cdot . \cdot \mathrm{rr}$ & $\mathrm{r}=\cdot / . .1$ & $\mathrm{r}=\cdot / 1 \mathrm{r}$. & $\mathrm{r}=-\cdot / r+q$ & $r=-\cdot / r \mid \theta$ & خم شدن به جِ & \\
\hline $\mathrm{P}=\cdot V G \Lambda$ & $\mathrm{P}=\cdot / \cdot .9$ & $\mathrm{P}=\cdot / 9 / r$ & $\mathrm{P}=\cdot / 999$ & $\mathrm{P}=\cdot \mid \Delta r F$ & $\mathrm{P}=.1 .9 \mathrm{~F}$ & $\mathrm{P}=\cdot / r 91$ & & \\
\hline $11 \% / \wedge 9 \pm V / 19$ & $|r T / A G \pm F / A|$ & $\| / r / 19 \pm V / q V$ & $1 \cdot 9 / \mathrm{V} 9 \pm N / \cdot V$ & $1 \cdot N / 4 \cdot \pm V / r^{\prime}$ & $\| / N / 99 \pm V / \cdot V$ & $\| / N / \Delta \Lambda \pm 9 / \Lambda \Lambda$ & & \\
\hline $\mathrm{r}=-\cdot / \mathrm{rr}$. & $\mathrm{r}=-\cdot / r \wedge \varphi$ & $\mathrm{r}=\cdot \cdot \cdot \cdot \mathrm{rF}$ & $\mathrm{r}=\cdot \cdot 9 \Delta \phi$ & $r=-\cdot /|\Lambda|$ & $\mathrm{r}=-. .1 .19$ & $\mathrm{r}=\cdot / r F \Delta$ & خم شدن (درجه) & \\
\hline $\mathrm{P}=\cdot / / 1 \mathrm{~V}$ & $\mathrm{P}=\cdot \cdot \cdot v q$ & $\mathrm{P}=\cdot / V T F$ & $\mathrm{P}=\cdot|\cdots|$ & $\mathrm{P}=\cdot \pi \wedge \varphi$ & $\mathrm{P}=\cdot / q \uparrow r$ & $\mathrm{P}=\cdot \cdot \cdot \lambda \mathrm{F}$ & & \\
\hline$r r / v \Delta \pm r / v q$ & $r \Psi / r v \pm r / \Lambda 1$ & $\kappa \psi / \cdot \varphi \pm r / \Lambda \Delta$ & $F r / T / \pm T / V V$ & $F / / A F \pm r / N G$ & $r r / q r \pm r / q \Delta$ & $F r / V Y \pm r / \Delta r$ & & تنه \\
\hline $\mathrm{r}=\cdot \pi \varphi$ & $r=-.1 .9 r$ & $\mathrm{r}=\cdot \cdot \cdot \cdot \Delta \Lambda$ & $r=-. / . r q$ & $\mathrm{r}=-. / .1 \mathrm{~T}$ & $\mathrm{r}=-\cdot / / \mathrm{r}$. & $r=\cdot / / T r$ & 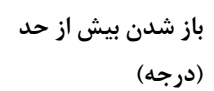 & \\
\hline $\mathrm{P}=\cdot / / \Lambda r$ & $\mathrm{P}=\cdot \mid q \wedge r$ & $\mathrm{P}=\cdot / V A r$ & $\mathrm{P}=\cdot / \Lambda \Delta V$ & $\mathrm{P}=\cdot / 9 \Delta \varphi$ & $\mathrm{P}=\cdot / \Delta V V$ & $\mathrm{P}=\cdot|\Delta \Delta|$ & & \\
\hline$r \Lambda / Q \varphi \pm r / \cdot \Delta$ & $r v / . q \pm r / 4 \varphi$ & $r q / r f \pm r / / r$ & $r N / \Delta \wedge \pm r / f$. & $r q / r \cdot \pm r / \Delta r$ & $r V / r r \pm T / r)$ & $r N / \Delta F \pm r / I I$ & & \\
\hline $\mathrm{r}=\cdot / 4 \mid \Lambda$ & $\mathrm{r}=\cdot / R 94$ & $\mathrm{r}=-\cdot / 191$ & $\mathrm{r}=-\cdot / r 94$ & $\mathrm{r}=\cdot / 199$ & $\mathrm{r}=-\cdot / 1 \Lambda 1$ & $\mathrm{r}=\cdot / \pi r \Delta$ & خم شدن به راست & \\
\hline $\mathrm{P}=\cdot / \cdot r V$ & $\mathrm{P}=\cdot / r r v$ & $\mathrm{P}=\cdot / f+r$ & $\mathrm{P}=\cdot / 19$ & $\mathrm{P}=\cdot / 4 r$. & $\mathrm{P}=\cdot / \pi 91$ & $\mathrm{P}=\cdot / r v$ & & \\
\hline$r r / r \Delta \pm 1 / A V$ & $r q / V r \pm 1 / 9 r$ & $r r / q \cdot \pm r / \cdot r$ & $r 1 / . . \pm 1 / q r$ & $r \cdot / \Delta q \pm 1 / \wedge 9$ & $r \mid / \Delta F \pm 1 / 9 \Lambda$ & $r r / r V \pm 1 / 9 \varphi$ & & \\
\hline $\mathrm{r}=\cdot / \mathrm{rAr}$ & $\mathrm{r}=\cdot / 1 \uparrow \Lambda$ & $\mathrm{r}=-\cdot \cdot \cdot \mathrm{vF}^{\mathrm{C}}$ & $\mathrm{r}=-\cdot / / f$. & $\mathrm{r}=\cdot . \cdot 9 \mathrm{r}$ & $\mathrm{r}=\cdot / r \cdot v$ & $\mathrm{r}=\cdot / \cdot \cdot \Lambda$ & خمم شدن به جِ & \\
\hline $\mathrm{P}=\cdot \cdot * \varphi \Delta$ & $\mathrm{P}=\cdot|\Delta|$ & $\mathrm{P}=\cdot / V r \Delta$ & $\mathrm{P}=\cdot|\Delta| r$ & $\mathrm{P}=\cdot / 9 \Delta \Lambda$ & $\mathrm{P}=\cdot / \pi r r$ & $\mathrm{P}=\cdot / 9 \vee 1$ & & \\
\hline $199 / K 4 \pm r / 4 r$ & $19 r / .9 \pm r / T r$ & $199 / \cdots \pm r / r r$ & $19 \cdot \pi \Delta \pm f / r \Delta$ & $191 / \cdot 1 \pm f / 1 r$ & $19 r / 9 r \pm r / 91$ & $199 / 99 \pm r / \Lambda$ & & \\
\hline$r=\cdot / 11 \phi$ & $\mathrm{r}=-\cdot / T F r$ & $\mathrm{r}=-\cdot / r \Delta \Delta$ & $\mathrm{r}=-\cdot / / \mathrm{rV}$ & $\mathrm{r}=-\cdot \cdot \cdot \Delta \mathrm{A}$ & $\mathrm{r}=-\cdot / 1 \wedge \mathrm{F}$ & $r=\cdot / r r$. & خم شدن (درجه) & \\
\hline $\mathrm{P}=\cdot / \Delta \Delta q$ & $\mathrm{P}=\cdot / r v q$ & $\mathrm{P}=\cdot|\cdot \wedge|$ & $\mathrm{P}=\cdot / \Delta \Delta F$ & $\mathrm{P}=\cdot / v \wedge F$ & $\mathrm{P}=\cdot \pi \wedge q$ & $\mathrm{P}=\cdot / r \Lambda 1$ & & \\
\hline$\kappa V / \Delta V \pm \kappa / r$. & $\Delta r / q 1 \pm F / \Lambda F$ & 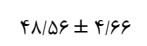 & $\Delta \cdot / v \Delta \pm F / 99$ & $\Delta F / q F \pm F / r \Delta$ & $\Delta \mid / / V \pm r / 9 \varphi$ & $F \& / q T \pm F / V G$ & & \\
\hline $\mathrm{r}=\cdot / 191$ & $\mathrm{r}=-\cdot / 194$ & $\mathrm{r}=-\cdot / \mathrm{FVT}^{-}$ & $\mathrm{r}=-\cdot / / \wedge \varphi$ & $\mathrm{r}=-\cdot / \| \uparrow \wedge$ & $\mathrm{r}=-\cdot / 190$ & $\mathrm{r}=\cdot / / r \Lambda$ & 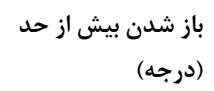 & \\
\hline $\mathrm{P}=\cdot \pi r$ & $\mathrm{P}=\cdot / 4 \varepsilon V$ & $\mathrm{P}=\cdot / \cdot 1 \mathrm{~V}$ & $\mathrm{P}=\cdot r \lambda \psi$ & $\mathrm{P}=\cdot / 4 \lambda \psi$ & $\mathrm{P}=\cdot / F \psi t$ & $\mathrm{P}=\cdot / \theta \cdot r$ & & شانه \\
\hline $\mid \gamma q / \varangle \varepsilon \pm r / \& \Lambda$ & $19 \mathrm{~V} / .9 \pm F / T F$ & $\mid \Lambda \cdot / r \Lambda \pm r / \Delta \varphi$ & $\mid V T / G T \pm F / T$. & $|V \cdot / v e \pm r / l|$ & |Vr/Vq $\pm r / \mid r$ & IVV/VTE \pm r/qT & & \\
\hline $\mathrm{r}=\cdot / r v q$ & $\mathrm{r}=\cdot / 1 \cdot f$ & $\mathrm{r}=-\cdot \cdot \cdot . \Delta 1$ & $\mathrm{r}=-\cdot / r F r$ & $r=.1 .99$ & $\mathrm{r}=-\cdot / 19 \Delta$ & $r=\cdot / \cdot v r$ & دور شدن (درجه) & \\
\hline $\mathrm{P}=\cdot / * \psi \mathrm{FV}$ & $\mathrm{P}=\cdot \mid q 4 \varphi$ & $\mathrm{P}=\cdot|\wedge|$ & $\mathrm{P}=\cdot / T T \Delta$ & $\mathrm{P}=\cdot / \mathrm{V} \ll r$ & $\mathrm{P}=\cdot / f \kappa$ & $\mathrm{P}=\cdot / V T r$ & & \\
\hline $91 / \cdot f \pm r / 19$ & $\Delta N / \Delta \cdot \pm r / N F$ & $91 / 1 \cdot \pm r / 4 q$ & $\Delta N / \Delta F \pm r / T V$ & $\Delta \varphi / \Delta \varphi \pm r / .$. & $\varphi / / \Lambda \cdot \pm r / \Delta \varphi$ & $q 1 / r V \pm r / q V$ & نزديك شدن بيش از & \\
\hline $\mathrm{r}=\cdot / \pi r$. & $\mathrm{r}=\cdot \pi \mathrm{r}$. & $\mathrm{r}=\cdot / \cdot \cdot \Delta$ & $\mathrm{r}=\cdot \cdot \cdot r \mathrm{rV}$ & $\mathrm{r}=\cdot|\pi T|$ & $\mathrm{r}=\cdot / 1 \uparrow \theta$ & $r=\cdot / \cdot r$ & حد (درجه) & \\
\hline
\end{tabular}




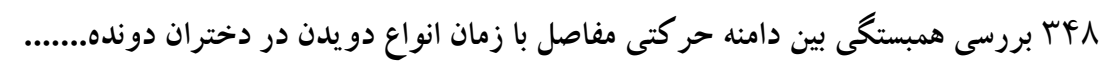

\begin{tabular}{|c|c|c|c|c|c|c|c|c|}
\hline $\mathrm{P}=. / .9 \mathrm{~V}$ & $\mathrm{P}=\cdot /|r|$ & $\mathrm{P}=\cdot / 9 \Lambda$. & $\mathrm{P}=\cdot / \Lambda A T$ & $\mathrm{P}=\cdot / 1 / \mathrm{V}$ & $\mathrm{P}=\cdot / \omega \cdot$ & $\mathrm{P}=\cdot / 99$. & & \\
\hline $\mid r \Delta / \Lambda \varphi \pm F / r r$ & $\mid r G / F \Delta \pm \Delta / F T$ & $|r \Delta / F F \pm F / \Lambda|$ & $|r q / r \Delta \pm| / N \mid$ & $\mid r F / . F \pm F / N T$ & $\mid r F / q \Delta \pm F / q r$ & $|f| / F T \pm 1 / 99$ & & \multirow{6}{*}{ آرنج } \\
\hline $\mathrm{r}=\cdot / r v q$ & $\mathrm{r}=-\cdot / 194$ & $\mathrm{r}=\cdot / 1 \vee 9$ & $\mathrm{r}=\cdot / 11$ & $\mathrm{r}=\cdot / T V V$ & $\mathrm{r}=\cdot / 4 \cdot v$ & $\mathrm{r}=-\cdot \cdot \cdot \Delta \mathrm{A}$ & خم شدن (درجه) & \\
\hline $\mathrm{P}=\cdot|| \Delta \mid$ & $\mathrm{P}=\cdot / r \Lambda \Lambda$ & $\mathrm{P}=\cdot / r q 4$ & $\mathrm{P}=\cdot 19 \cdot 1$ & $\mathrm{P}=\cdot / \wedge \Lambda$ & $\mathrm{P}=\cdot / * \wedge$ & $\mathrm{P}=\cdot / v \wedge$ & \multirow{4}{*}{ 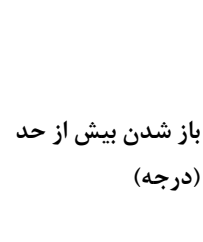 } & \\
\hline $\mid N / F \pm \cdot / r V$ & $|N| \cdot \Delta \pm \cdot / r$ & $\mid N / \cdot \cdot \pm \cdot / \% q$ & $|N / r| \pm \cdot / r F$ & $\mid N / T \cdot \pm \cdot / r \Delta$ & $|N / r| \pm \cdot / r \Delta$ & $|N| \cdot \pm \cdot /{ }^{\prime} \Delta$ & & \\
\hline $\mathrm{r}=\cdot / 1 \wedge 9$ & $\mathrm{r}=\cdot / 111$ & $\mathrm{r}=\cdot / \pi G 4$ & $\mathrm{r}=\cdot / 1 \Delta \mathrm{V}$ & $\mathrm{r}=\cdot / 1 \cdot 1$ & $\mathrm{r}=-\cdot / 004$ & $\mathrm{r}=\cdot / \pi \mid$ & & \\
\hline $\mathrm{P}=\cdot \pi r T$ & $\mathrm{P}=\cdot / g r F$ & $\mathrm{P}=\cdot \cdot \cdot v{ }^{4}$ & $\mathrm{P}=\cdot / 4 q 4$ & $\mathrm{P}=\cdot / 9 \pi T$ & $\mathrm{P}=\cdot / 9 \wedge \Delta$ & $\mathrm{P}=\cdot / / \tau \psi$ & & \\
\hline$r \Delta / r Y \pm 1 / 9 r$ & $r q / \Lambda 9 \pm 1 / 9 \Lambda$ & $r q / . \varphi \pm 1 / q r$ & $r \Delta|q| \pm 1 / v \mid$ & $r Y / V G \pm I / V F$ & $r q / r q \pm 1 / v r$ & $r V / r \Delta \pm 1 / \uparrow 1$ & \multirow{3}{*}{ 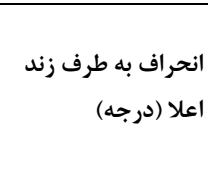 } & \multirow{12}{*}{ دمت } \\
\hline$r=\cdot / 1 \wedge r$ & $\mathrm{r}=\cdot / r \wedge \Delta$ & $r=\cdot / \cdot r$. & $\mathrm{r}=\cdot / \pi / f$ & $\mathrm{r}=-\cdot / / \mathrm{rV}$ & $\mathrm{r}=\cdot / \pi+4$ & $\mathrm{r}=\cdot / 1 / f$ & & \\
\hline $\mathrm{P}=\cdot / r \Delta \Delta$ & $\mathrm{P}=\cdot \cdot \cdot v \mathrm{VV}$ & $\mathrm{P}=\cdot / \wedge \wedge \varphi$ & $\mathrm{P}=\cdot \pi / 4$ & $\mathrm{P}=\cdot|\Delta| f$ & $\mathrm{P}=\cdot \pi f v$ & $\mathrm{P}=\cdot / \Delta \vee \Lambda$ & & \\
\hline$\Delta G / V q \pm 1 / 9 T$ & $91 / r+ \pm 1 / 99$ & $\Delta V / r f \pm Y / \cdot F$ & $\Delta V / \Delta \wedge \pm 1 / 9 \varphi$ & $\Delta N / \cdots \pm 1 / 9 \gamma$ & $\Delta \Lambda / \Lambda \Lambda \pm 1 / 9 \Lambda$ & $\Delta V / 9 T \pm 1 / \Lambda \varphi$ & \multirow{3}{*}{ اسفل (درجه) افه برف زند } & \\
\hline$r=-\cdot / 19$. & $\mathrm{r}=\cdot / 11 \%$ & $\mathrm{r}=\cdot 1 . .9$ & $\mathrm{r}=\cdot / \pi r q$ & $\mathrm{r}=-\cdot / 1 r q$ & $r=-. / .1 r$ & $\mathrm{r}=-\cdot / T S T$ & & \\
\hline $\mathrm{P}=\cdot / F \mid \Delta$ & $\mathrm{P}=\cdot / 1 \Delta \mathrm{V}$ & $\mathrm{P}=\cdot / 999$ & $\mathrm{P}=\cdot / 119$ & $\mathrm{P}=\cdot / 0 \cdot 9$ & $\mathrm{P}=\cdot / 901$ & $\mathrm{P}=\cdot / 19 \diamond$ & & \\
\hline $189 / 91 \pm 1 / 19$ & $v f / \cdot f \pm 1 / .9$ & $V g / 4 F \pm 1 / r q$ & $V \Delta / r \Lambda \pm 1 / r r$ & $V g / r f \pm 1 /$. & $V F / V \Delta \pm 1 / r q$ & $V \Delta / \Lambda \Delta \pm 1 / r r$ & \multirow{3}{*}{ خم شدن (درجه) } & \\
\hline $\mathrm{r}=\cdot / T F T$ & $\mathrm{r}=\cdot / \cdot \Delta$ & $\mathrm{r}=-\cdot / Y \wedge \varphi$ & $\mathrm{r}=-\cdot / r q r$ & $\mathrm{r}=-\cdot / / 9 \varphi$ & $\mathrm{r}=-\cdot / 11 \wedge$ & $\mathrm{r}=-\cdot \cdot \cdot \cdot \mathrm{r} \mid$ & & \\
\hline $\mathrm{P}=\cdot \cdot \cdot v \Delta$ & $\mathrm{P}=\cdot / \wedge r \Delta$ & $\mathrm{P}=\cdot / 190$ & $\mathrm{P}=\cdot / 199$ & $\mathrm{P}=\cdot \pi r q$ & $\mathrm{P}=\cdot / \Delta \wedge r$ & $\mathrm{P}=\cdot / v r$ & & \\
\hline $91 / \wedge 9 \pm 1 / 94$ & $9 \Delta / \Delta \Delta \pm 1 / 9 \uparrow$ & $41 / 4 \cdot \pm r / 1 r$ & $s 4 / \cdot r \pm 1 / \lambda r$ & G\&/VG I/VD & $q T / 4 \varepsilon \pm r / / Q$ & Gr/rr $\pm r / \cdot 1$ & \multirow{3}{*}{ باز شدن (درجه) } & \\
\hline $\mathrm{r}=-\cdot / 19 \mathrm{r}$ & $\mathrm{r}=\cdot / r 9 \mathrm{D}$ & $r=.1 \cdot r r$ & $\mathrm{r}=-\cdot / / r \Lambda$ & $\mathrm{r}=\cdot / r \Delta$ & $\mathrm{r}=-\cdot / \mid \Delta f$ & $\mathrm{r}=.1 .9 \mathrm{r}$ & & \\
\hline $\mathrm{P}=\cdot|f|$ & $\mathrm{P}=\cdot / \cdot 9 \Delta$ & $\mathrm{P}=\cdot / \Lambda V{ }^{4}$ & $P=\cdot / 019$ & $\mathrm{P}=\cdot \pi r \Lambda$ & $\mathrm{P}=\cdot|q v|$ & $\mathrm{P}=\cdot 19 \Delta \Delta$ & & \\
\hline $11 r / 91 \pm r / \Delta r$ & $1 \cdot N / G Y \pm Y / \Delta F$ & $111 / 9 r \pm r / 91$ & $1 \cdot N / 99 \pm r / 9 r$ & $\| r / r \wedge \pm r / 9 r$ & $1 \cdot N / \Lambda \Lambda \pm r / \Delta r$ & $11 \cdot / 1 r \pm r / 1 \Lambda$ & \multirow{3}{*}{ خم شدن (درجه) } & \multirow{12}{*}{ 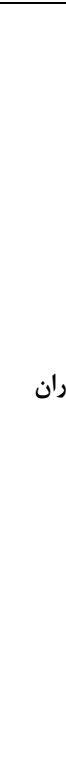 } \\
\hline $\mathrm{r}=\cdot / 1 \cdot v$ & $\mathrm{r}=-\cdot \cdot r \cdot \lambda$ & $\mathrm{r}=\cdot / \cdot \omega$ & $\mathrm{r}=-\cdot / r V r$ & $\mathrm{r}=-\cdot . \cdot 11$ & $\mathrm{r}=-\cdot / / r \mathrm{r}$ & $\mathrm{r}=-\cdot \cdot \cdot 1$. & & \\
\hline $\mathrm{P}=\cdot / \Delta \wedge\rangle$ & $\mathrm{P}=\cdot / r \Delta r$ & $\mathrm{P}=\cdot / 9 \Lambda$. & $\mathrm{P}=\cdot / 199$ & $\mathrm{P}=\cdot / 9 r 4$ & $\mathrm{P}=\cdot \Delta \mu r$ & $\mathrm{P}=\cdot / 991$ & & \\
\hline Fr/ATE \pm T/Fr & $r \Delta / r r \pm r / \Delta$. & $r r / v g \pm r / \lambda$. & $r \Lambda / r \Lambda \pm r / 19$ & $r q / \Lambda \Lambda \pm r / \& q$ & $\nvdash / \cdot \wedge \pm r / \Lambda V$ & $F r / r) \pm r / \Delta \mid$ & \multirow{3}{*}{ 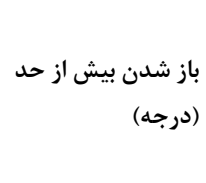 } & \\
\hline $\mathrm{r}=\cdot / \pi 9 \mathrm{r}$ & $r=-\cdot / \gamma$. & $r=-\cdot / \cdot \Delta$. & $\mathrm{r}=\cdot / \mathrm{TVA}$ & $\mathrm{r}=-\cdot / \mathrm{TVF}$ & $\mathrm{r}=\cdot / 1 \mathrm{f}$. & $\mathrm{r}=\cdot \cdot \cdot \Delta \Delta$ & & \\
\hline $\mathrm{P}=\cdot / \cdot r \Lambda$ & $\mathrm{P}=\cdot / \uparrow \Delta$ & $\mathrm{P}=\cdot|\lambda| \mid$ & $\mathrm{P}=\cdot / / \Lambda \Lambda$ & $\mathrm{P}=\cdot / / \wedge \Delta$ & $\mathrm{P}=\cdot / \Delta \mid \Delta$ & $\mathrm{P}=\cdot / v \wedge \Lambda$ & & \\
\hline$\Delta V / G \wedge \pm 1 / \Lambda r$ & $\Delta r / V Y \pm r / \cdot \Delta$ & $\Delta \mathrm{V} / \cdot \cdot \pm 1 / \wedge \Delta$ & $\Delta V / \Delta f \pm r / / \varphi$ & $\Delta V / 9 \varphi \pm r / . q$ & $\Delta \Delta / r r \pm r / q 9$ & $\Delta Q / \cdot F \pm 1 / V V$ & \multirow{3}{*}{ دور شدن (درجه) } & \\
\hline $\mathrm{r}=\cdot \pi \varphi$ & $\mathrm{r}=-. .1 .9 \mathrm{r}$ & $\mathrm{r}=-\cdot / r q 4$ & $\mathrm{r}=-\cdot / r q \mathrm{v}$ & $\mathrm{r}=-\cdot|| r \mid$ & $\mathrm{r}=-\cdot / \pi r$. & $r=\cdot / 1 \cdot r$ & & \\
\hline $\mathrm{P}=\cdot /|\wedge|$ & $\mathrm{P}=\cdot / v \wedge \Delta$ & $\mathrm{P}=\cdot / / \Delta r$ & $\mathrm{P}=\cdot \cdot \cdot \Delta f$ & $\mathrm{P}=\cdot \mid \Delta \& r$ & $\mathrm{P}=\cdot / r \Lambda$ & $\mathrm{P}=\cdot|q| \Lambda$ & & \\
\hline$r G / V I \pm r / \Lambda$. & $r N / \cdot q \pm r / r \Lambda$ & $r \digamma / M \Lambda \pm r / q \uparrow$ & $r V / / V \pm r / 9 \vee$ & $r \Delta / 9 \varphi \pm r / q \gamma$ & $r \Delta / r r \pm r / q q$ & $r V / \Lambda I \pm r / \Delta \Lambda$ & \multirow{3}{*}{ حد (درجى شدن بيش از } & \\
\hline $\mathrm{r}=\cdot \cdot \cdot \cdot \psi$ & $\mathrm{r}=-\cdot / . .+4$ & $\mathrm{r}=\cdot / T \Delta S$ & $\mathrm{r}=\cdot / \cdot \mathrm{r}$. & $\mathrm{r}=\cdot \mid \Delta \mathrm{r}^{\prime}$ & $\mathrm{r}=\cdot / f \mathrm{Fr}$ & $\mathrm{r}=-. / 1.4$ & & \\
\hline $\mathrm{P}=\cdot / 9 \wedge r$ & $\mathrm{P}=\cdot / 9 \wedge \mathrm{V}$ & $\mathrm{P}=\cdot / \pi \mid \varphi$ & $\mathrm{P}=\cdot / 9 Y \varphi$ & $\mathrm{P}=\cdot / \cdot . \varphi$ & $P=\cdot / \Delta \cdot \Delta$ & $\mathrm{P}=\cdot 19 \cdot 9$ & & \\
\hline
\end{tabular}




\begin{tabular}{|c|c|c|c|c|c|c|c|c|}
\hline $\mid r \Delta / / F \pm r / \cdot r$ & $1 r \cdot \pi r \pm 1 / 19$ & $\mid T H / g \cdot \pm T / T r$ & $\mid r T / \Delta \Lambda \pm 1 / 9 Y$ & IKT/VG $\pm 1 / A S$ & $|r| / 9 r \pm 1 / 19$ & $\mid r F / \Delta F \pm T / / r$ & \multirow{3}{*}{ خم شدن (درجه) } & \multirow{3}{*}{ زانو } \\
\hline $\mathrm{r}=\cdot / \mu \cdot 1$ & $\mathrm{r}=-\cdot / \cdot * \Lambda$ & $\mathrm{r}=-\cdot / / 1 \mathrm{f}$ & $r=-.1 \cdot v q$ & $\mathrm{r}=\cdot / .1 \mathrm{~V}$ & $\mathrm{r}=\cdot / 1 / \phi$ & $\mathrm{r}=-\cdot / / \Delta \Delta$ & & \\
\hline $\mathrm{P}=\cdot / / r$. & $\mathrm{P}=\cdot / \lambda r T$ & $\mathrm{P}=\cdot / \Delta \wedge \mathrm{V}$ & $\mathrm{P}=\cdot / N \backslash \Delta$ & $\mathrm{P}=\cdot / 9 r \Delta$ & $\mathrm{P}=\cdot / \Delta q T$ & $\mathrm{P}=\cdot / \uparrow \Delta$. & & \\
\hline$r \cdot|\Delta F \pm \cdot| q \psi$ & $r \cdot / r T \pm \cdot / \Lambda$. & $\pi \cdot / 9 \cdot \pm \cdot / V \cdot$ & $r \cdot / r \wedge \pm \cdot / \Lambda \Delta$ & $\zeta / 9 \Lambda \pm \cdot / 9 \Delta$ & $r \cdot / r T \pm \cdot / V \varphi$ & $19 / \Delta \Lambda \pm \cdot / V \Lambda$ & \multirow{3}{*}{ به ساق پا (درجه شدن ينجه ها } & \multirow{6}{*}{ مج يا } \\
\hline$r=-\cdot / \cdot \mu_{f}$ & $\mathrm{r}=-\cdot / \cdot \cdot \Delta$ & $r=-\cdot / 194$ & $\mathrm{r}=-\cdot / \pi \wedge 9$ & $\mathrm{r}=\cdot / \cdot \varphi$. & $\mathrm{r}=-\cdot / 494$ & $\mathrm{r}=\cdot \cdot / \cdot 1$ & & \\
\hline $\mathrm{P}=\cdot /$ NST & $\mathrm{P}=\cdot / 911$ & $\mathrm{P}=\cdot / T \Delta \varphi$ & $\mathrm{P}=.1 .4$ & $\mathrm{P}=\cdot / \lambda \uparrow \lambda$ & $\mathrm{P}=\cdot 1 \cdot \mathrm{r}$ & $\mathrm{P}=\cdot / 991$ & & \\
\hline$G 9 / \Gamma T \pm r / \Delta$. & $99 / \cdots \pm 1 / 9$. & $9 \Delta / 19 \pm T / V 1$ & $99 / T \Delta \pm T / T F$ & $G 9 / V Y \pm 1 / M \Lambda$ & $s F / / V \pm r / r q$ & $9 \Delta / 9 T \pm Y / \Delta \Lambda$ & \multirow{3}{*}{ 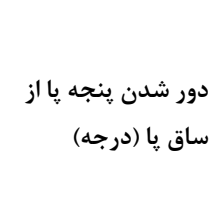 } & \\
\hline $\mathrm{r}=-\cdot / \cdot \mathrm{VA}$ & $r=\cdot 1 \cdot v \varphi$ & $r=\cdot / \cdot r r$ & $\mathrm{r}=-\cdot / \mathrm{rr}$ & $\mathrm{r}=\cdot / r q 4$ & $\mathrm{r}=-\cdot / 041$ & $\mathrm{r}=\cdot 1 \cdot r 4$ & & \\
\hline $\mathrm{P}=\cdot / 994$ & $P=\cdot V r \Lambda$ & $\mathrm{P}=\cdot / 994$ & $\mathrm{P}=\cdot / r \cdot$ & $\mathrm{P}=\cdot / 1 \Delta \varphi$ & $P=\cdot / \Lambda \uparrow v$ & $\mathrm{P}=\cdot / \wedge \varphi$. & & \\
\hline$r G / V Q \pm r / \uparrow \wedge$ & $r \cdot / 9 \Lambda \pm r / 9 \Lambda$ & $r F / V Y \pm r / r q q$ & $r \Delta / v \Delta \pm r / \Lambda r$ & $r / / r \Lambda \pm r / \Delta q$ & $r r / \Lambda \cdot \pm r / \kappa$. & $r r / l r \pm r / r r$ & \multirow{3}{*}{ 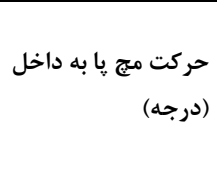 } & \multirow{6}{*}{ تحت } \\
\hline$r=\cdot / \cdot r^{f}$ & $\mathrm{r}=-\cdot / T^{\prime} f$ & $\mathrm{r}=-\cdot / \varphi \Delta f$ & $\mathrm{r}=-\cdot / F+4$ & $\mathrm{r}=\cdot / 1 f q$ & $\mathrm{r}=-\cdot / \pi \mid$. & $\mathrm{r}=-\cdot \mid r+1$ & & \\
\hline $\mathrm{P}=\cdot / 9 \cdot r$ & $\mathrm{P}=\cdot / 1 \Delta \Delta$ & $\mathrm{P}=\cdot / \cdot r r$ & $\mathrm{P}=\cdot / \cdot r$. & $\mathrm{P}=\cdot / f v V$ & $\mathrm{P}=. / \pi \varphi$ & $\mathrm{P}=\cdot / \pi r \varphi$ & & \\
\hline$r \Delta / \cdot v \pm 1 / v q$ & $r \mid / \uparrow 1 \pm 1 / \wedge q$ & $K F / T F \pm 1 / A F$ & $r r / N I \pm r / l$. & $r F / F \wedge \pm r / \cdot q$ & $r r / F r \pm 1 / 9 F$ & $r r / r r \pm 1 / A r$ & \multirow{3}{*}{ 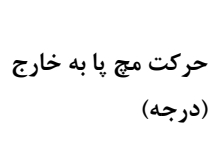 } & \\
\hline $\mathrm{r}=\cdot||+\mid$ & $\mathrm{r}=-\cdot / f+$. & $\mathrm{r}=-\cdot / r \Delta r$ & $r=-\cdot / r \cdot r$ & $r=-\cdot 1 \cdot \psi \wedge$ & $\mathrm{r}=-\cdot / \cdot * \mathrm{v}$ & $\mathrm{r}=-\cdot / / \lambda \mathrm{V}$ & & \\
\hline $\mathrm{P}=\cdot / q^{\prime} \gamma^{4}$ & $\mathrm{P}=\cdot \cdot \cdot \varphi$. & $\mathrm{P}=\cdot \cdot / \cdot \Delta q$ & $\mathrm{P}=\cdot / 1 \Delta T$ & $\mathrm{P}=\cdot|\wedge| \wedge$ & $P=\cdot / A T V$ & $\mathrm{P}=\cdot / \pi 4$. & & \\
\hline
\end{tabular}

رابطه منفى معنى دار وجود دارد. در دوى • • ال متر، بين باز

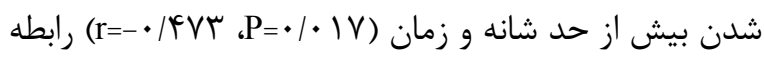
منفى معنى دار وجود دارد. در دوى ... متر، بين باز شدن

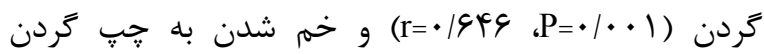

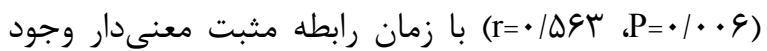

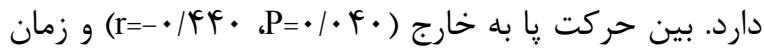
رابطه منفى معنى دار وجود دارد. در دوى .أ متر

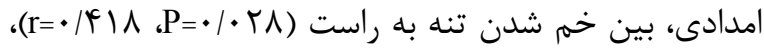

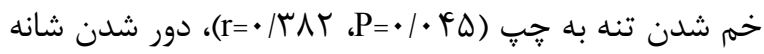
و بين باز شدن بيش از حد ران (r=/KV9 P=•/FV)
نتايج آزمونهاى ضريب همبستكى Pearson نشان داد كه در دوى •و متر، بين دامنه حركتى هيج يك از مفاصل و زمان دوى •9 متر رابطه معنىدار وجود ندارد. در دوى

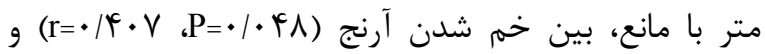
زمان رابطه مثبت معنىدار و بين نزديك شدن ينجه يا به

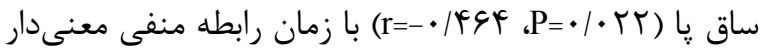
وجود دارد. در دوى • • متر، بين نزديك شدن بيش از حد

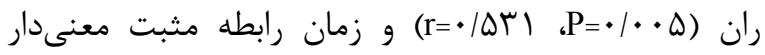
وجود دارد. در دوى •1 متر، بين خم شدن تنه

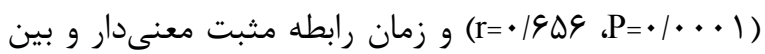

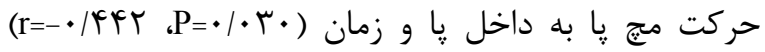


•هّ بررسى همبستخى بين دامنه حر كتى مفاصل با زمان انواع دويدن در دختران دونده...............

دويدن •4 متر با مانع كاهش يافته و زمان كم شده و ركورد

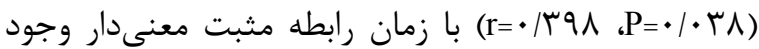

بهبود مىيابند.

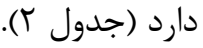

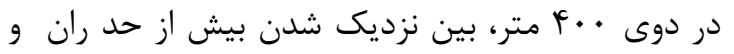

بحث

زمان دوى • · متر رابطه مثبت معنى دار وجود دارد. يعنى

با افزايش نزديك شدن بيش از حد ران، زمان دوى . F

متر بيشتر شده و ركورد بدتر مىشود. اين امر ناشى از اين

امر است كه حركات زائد و جانبى اندامهاى بدن منجر به

كاهش عملكرد در دوهاى مختلف و آسيب مفاصل مى شود

[•r]. در دوى . .1 متر، بين خم شدن تنه و زمان دوى

• • متر رابطه مثبت معنىدار و بين حركت مج يا به داخل

״ا و زمان دوى · · متر رابطه منفى معنى دار وجود دارد.

يعنى با افزايش خم شدن تنه، زمان دوى · ㅅ متر بيشتر

شده و ركورد بدتر مىشود و با افزايش اينورشن پا، ركورد

دوى •1 متر كمتر شده و ركورد بهبود مىيابد. بين خم

شدن و باز شدن تنه كه ناشى از نيروهاى عرضى مىباشد و

سرعت دويدن رابطه معنى دار وجود دارد [سץ]]. بنابراين خم

شدن تنه در دوى •1 متر احتمالاً منجر به افزايش بيشتر

نيروهاى عرضى در تحقيق حاضر شده و در نتيجه زمان دوى

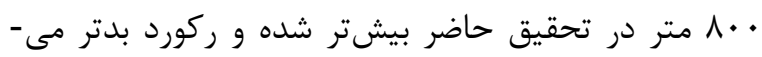

شود. از طرفى، همانطور كه قبلاً كَفته شد، نزديك شدن

ينجه پا به ساق و حركت مج پا به داخل در طى دويدن

برخى از ضربات و نيروهاى اصطكاكى ناشى از تماس يا با

زمين طى دويدن را جذب مىكند و كاهش مى دهد [ra].

بنابراين مى توان كفت با افزايش حركت مج يا به داخل،

برخى از ضربات و نيروهاى اصطكاكى ناشى از تماس يا با

يافتههاى تحقيق حاضر نشان داد در دوى •4 متر، بين

دامنه حركتى هيجيك از مفاصل با زمان دوى •4 متر رابطه

معنى دار وجود ندارد. در دوى •و متر با مانع، بين خم شدن

آرنج و زمان دوى •و متر با مانع رابطه مثبت معنىدار و بين

نزديك شدن ينجه يا به ساق با زمان دوى •4 متر با مانع

رابطه منفى معنىدار وجود دارد. يعنى با افزايش خم شدن

آرنج، زمان دوى •و متر با مانع بيشتر شده و ركورد بدتر

مىشود و با افزايش نزديك شدن ينجه يا به ساق، زمان دوى • متر با مانع كمتر شده و ركورد بهبود مىيابد. در توجيه

اين يافته جنين مىتوان كَفت كه حداكثر خم كردن آرنج در

طى دويدن بايد ·9 تا · . ا درجه باشد تا دستها به آرامى به سمت جلو و عقب نوسان كنند [YV-YN] اين حركت

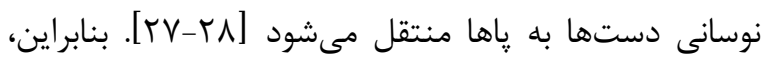
خم كردن بيش از حد دستها در تحقيق حاضر باعث اختلال در حركات نوسانى و هماهنگ دستها و پِاها شده [rV] و در نتيجه زمان دوى •4 متر كاهش يافته و ركورد بدتر مىشود. در مقابل، خم شدن ران، زانو و مج يا در طى دويدن برخى از ضربات و نيروهاى اصطكاكى ناشى از تماس يا با زمين طى دويدن را جذب مى كند و كاهش مىدهد [rq]. بنابراين مىتوان كَفت با افزايش نزديك شدن رنجه يا به ساق طى دوى •و متر با مانع در تحقيق حاضر برخى از ضربات و نيروهاى اصطلاكى ناشى از تماس يا با زمين طى 
و اين عدم تعادل بدن به حركات نوسانى دستها به پاها در طى دويدن منتقل مىشود و منجر به كاهش سرعت دويدن

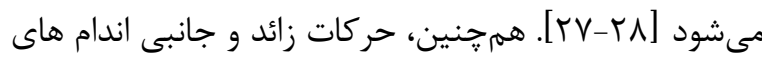
بدن منجر به كاهش عملكرد در دوهاى مختلف و آسيب مفاصل مىشود [•r]. در مقابل، حركت مج يا به داخل در طى دويدن برخى از ضربات و نيروهاى اصطكاكى ناشى از تماس يا با زمين طى دويدن را جذب مى كند و كاهش مى دهد [rq]. همرجنين، افزايش حركت مجز پا به خارج در دوندگًان دختر ماده . .. متر دويدن در تحقيق حاضر ناشى از انعطافيذيرى و قدرت بيشتر مفصل مج يا مىباشد كه منجر به بهبود زمان دوى .. متر مىباشد، يعنى عملكرد دوهاى استقامتى بهبود يافته و در نتيجه زمان دوى • . . . متر كاهش يافته و ركورد بهتر مىشود. در دوى • • أF متر امدادى، بين خم شدن تنه به راست، خم شدن تنه به جي، دور شدن شانه و باز شدن بيش از حد

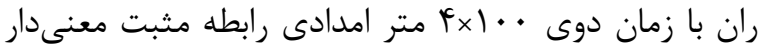
وجود دارد. يعنى با افزايش خم شدن تنه به راست، خم شدن تنه به جِ، دور شدن شانه و باز شدن بيش از حد ران، زمان دوى · · أl متر امدادى افزايش يافته و ركورد بدتر مىشود. همانطور كه كفته شد، حركات زائد و جانبى اندامهاى بدن منجر به كاهش عملكرد در دوهاى مختلف و آسيب مفاصل مىشود [ [ץ]. بنابراين افزايش حركات خم شدن تنه به راست، خمى شدن تنه به جֶٍ، دور شدن شانه و باز شدن بيش از حد ران كه حركات زائد و جانبى در دويدن امدادى مىباشند، منجر به افزايش زمان دوى • أl متر
زمين طى دويدن • ·1 متر كاهش يافته و زمان كمتر شده و ركورد بهبود مىيابند.

در دوى • •ها متر، بين باز شدن بيش از حد شانه و زمان دوى · • لها متر رابطه منفى معنى دار وجود دارد. يعنى با افزايش باز شدن بيش از حد شانه، زمان دوى · •ـا متر كاهش يافته و ركورد بهبود مىيابد. باز شدن بيش از حد شانه در دوى •ا1 متر در تحقيق حاضر باعث مىشود بازوها و دست راحت و آزاد بوده و به آرامى به سمت جلو و عقب نوسان يابند. عمل نوسانى دستها با عمل گياها در دويدن هماهنگ است. در نتيجه اين حركات نوسانى دستها به ياها متقل شده و موجب حركت سريعتر پاها مىشود [rV] [بنابراين با افزايش باز شدن بيش از حد شانه، حركات

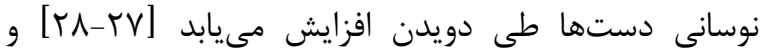
سرعت دويدن • •ها متر افزايش مىيابد و زمان دويدن كاهش يافته و ركورد بهبود مىيابد.

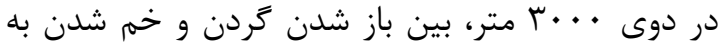

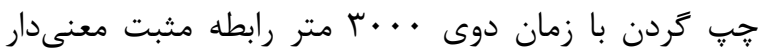
وجود دارد. در حالى كه بين حركت يا به خارج و زمان دوى •... . . متر رابطه منفى معنى دار وجود دارد. يعنى با افزايش باز شدن گردن و خم شدن گردن به جֶ، زمان دوى . . ." متر افزايش يافته و ركورد بدتر مىشود. در حالى كه با افزايش حركت يا به خارج، زمان دوى . .." متر كمتر شده و ركورد بهتر مى شود. افزايش باز شدن گردن و خم شدن گردن به جֶٍ در دوى ·. .." متر در تحقيق حاضر باعث مىشود بدن حالت تعادل خود را كمتر حفظ كند [اr، ^r] 
ديكر با همين عنوان در ردههاى ||-• ساله، ||-r| ساله و ا IV اله اله نيز مىتواند مفيد باشد.

\section{نتيجه}

نتايج تحقيق حاضر نشان داد كه بين دامنه حركتى مفاصل مختلف و زمان انواع دويدن رابطه معنى دارى وجود دارد. با توجه به نتايج به دست آمده در تحقيق حاضر به كليه مسئولين فدراسيون دو و ميدانى، مربيان و ورزش كاران توصيه مىشود هنگام انتخاب دوندگان دختر نخبه در سنين اوليه نوجوانى به دامنه حركتى مفاصل كه بيشتر تحت تأثير وراثت مىباشد توجه كنند و دوندكان مستعدى را كه دامنه حركتى مفاصل آنها به يافتههاى تحقيق حاضر نزديكتر است، در انواع رشتههاى دو به گَونهاى راهنمايى كنند تا علاوه بر صرفهجويى در وقت و هزينه، و با كسب ركوردهاى بهتر موفقيت بيشترى در رسيدن به اوج عملكرد ورزشى

$$
\text { كسب شود. }
$$

\section{تشكر و قدردانى}

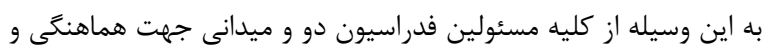

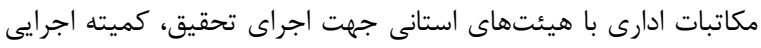

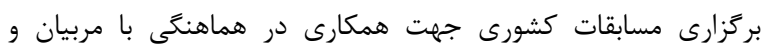

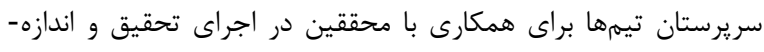

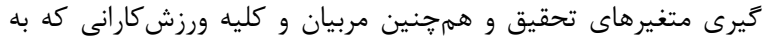

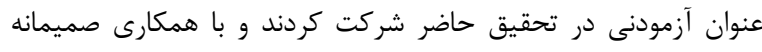

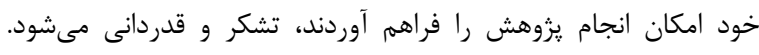

امدادى در تحقيق حاضر شده و ركورد بدتر مىشود. علتهاى احتمالى اين امر اين است كه حركات جانبى و زائد تنه، شانه و ران منجر به كاهش تعادل بدن و نيز كاهش هماهنگى حركات نوسانى دستها و پاها شده و سرعت

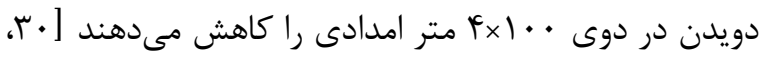
. [TV يافتههاى تحقيق حاضر در خصوص وجود رابطه بين دامنه حركتى مفاصل و زمان دويدن با يافتههاى Struzik و

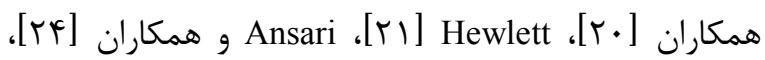
و همكاران [rol Inal همخوانى دارد. در حالى كه با يافتههاى Folland و همكاران [rrakaruk Makaruk و و Makak [rr] همخوانى ندارد. علت احتمالى اين ناهمخوانى، تفاوت در وسايل و ابزار اندازهخيرى، جنسيت آزمودنىها، تفاوتهاى آنترويومتريكى و فردى دوندًان [اب[] و مسافتهاى متفاوت دويدن در تحقيقات مختلف مىباشد. از جمله محدوديتهاى تحقيق حاضر مىتوان شرايط روانى، اجتماعى و اقتصادى آزمودنىها، خواب آزمودنىها در طى مسابقات و شب قبل از آزمونَيرى، و ميزان استرس و اضطراب آزمودنىها در طى مسابقات و روزهاى آزمون كيرى را نام برد كه بر عملكرد و زمان مسابقه اثرگذار مىباشد. ييشنهاد مىشود تحقيقى با همين عنوان در پيران انجام شود و با نتايج تحقيق حاضر مقايسه شود. انجام تحقيقات 


\section{References}

[1] Latt E, Jurimae J, Mäestu J, Purge P, Rämson R, Haljaste K, et al. Physiological, biomechanical and anthropometrical predictors of sprint swimming performance in adolescent swimmers. J Sports Sci Med 2010; 9(1): 398-404.

[2] Nasirzade AR, Ehsanbakhsh AR, Arghavani H, Aliakbari Beydokhti M, Moosavi SA. Predicting sprint performance of front-crawl swimming in young swimmers with an emphasis on biomechanical, muscle architectural and anthropometrical factors. Research in Sport Medicine and Technology 2012; 4(1): 1-13. [Farsi]

[3] Mejias JE, Bragada JA, Costa MJ, Reis VM, Garrido ND, Barbosa TM. Young masters vs. elite swimmers: Comparison of performance, energetics, kinematics and efficiency. International Sport Med Journal 2014; 15(1): 165-77.

[4] Ghasemzadeh Mirkolaee E. Studying the reasons for the failure and unsustainability of executing Iran's national athletics talent-identification model. Applied Research in Sport Management 2014; 2(14): 35-47. [Farsi]

[5] Ghasemzadeh Mirkolaee E, Razavi SMH, Amirnejad S. Investigating Factors Affecting Talent Development in Iranian Athletes. Journal of research in sport management and motor behavior 2014; 5(10): 37-46. [Farsi]

[6] Ghasemzadeh Mirkolaee E, Razavi SMH, Amirnejad S. A Mini-review of track and field's talentidentification models in Iran and some designated countries. Annals of Applied Sport Science 2013; 1(3): 17-28.

[7] Firoozi M, Razavi SMH, Farzan F. Investigating the Challenges and Problems of Iranian Medal Running, Sailing, and Swimming. Journal of Sport Management and Motor Behavior Research 2011; 8(15): 37-66. [Farsi]

[8] Mahmoudkhani MR, Dadashpour A, Hosseini SM. Determination of somatotype profile of male neonates of some Iranian ethnicities in athletics. Sport physiology 2013; 2(1): 129-40. [Farsi]

[9] Vaeyens R, Güllich A, Warr CR, Philippaerts R. Talent identification and promotion programmes of olympic athletes. Journal of sports sciences 2009; 27(13): 1367-80. 
[10] Hadavi F, Zarifi A. Talent identification and development model in Iranian athletics. World Journal of Sport Sciences 2009; 2(4): 248-53.

[11] Tønnessen E, Svendsen IS, Olsen IC, Guttormsen A, Haugen T. Performance Development in Adolescent Track and Field Athletes According to Age, Sex and Sport Discipline. PLoS One 2015; 4(1): 1-10.

[12] Malina RM, Slawinska T, Ignasiak Z, Rozek K, Kochan K, Domaradzki J, et al. Sex differences in growth and performance of track and field athletes 11-15 Years. J Hum Kinet 2010; 24(1): 79-85.

[13] Boccia G, Moisè P, Franceschi A, Trova F, Panero D, La Torre A, et al. Career performance trajectories in track and field jumping events from youth to senior success: The importance of learning and development. Plos one 2017; 12(1): 1-15.

[14] Lewandowska J, Buœko K, Pastuszak A, Boguszewska K. Somatotype Variables Related to Muscle Torque and Power in Judoists. J Hum Kinet 2011; 30(1): 821.

[15] Ackland TR, Elliott B, Bloomfield J. Applied anatomy and biomechanics in sport. Human Kinetics Champaign 2009; 1(1): 366.

[16] Roger E, Eston RG, rielly T. kinonthropometry and exercise physiology laboratory manual: teste, procedures ans data: Taylor and Francis 2009; 32(2): 353.

[17] Piter W, Bercander LT, Center O. somatotype of national elite combative sport athletes. Brazillian journal of Biomotricity 2009; 3(1): 21-30.

[18] Knechtle B, Knechtle P, Rosemann T. No association of skin-fold thicknesses and training with race performance in male ultra-endurance runners in a $\mathrm{rF}$ hour run. J Hum Sport Exerc 2011; 6(1): 94-100.

[19] Modses M, Jurimae J, maestu J. Anthopometric and physiological determination s of runnige performance in middle and long distancs runners. Kineziology 2013; 45(2): 154-62.

[20] Struzik A, Konieczny G, Grzesik K, Stawarz M, Winlarski S, Rokita A. Relationship between lower limbs kinematic variables and effectiveness of sprint during maximum velocity phase. Acta of Bioengineering and Biomechanics 2015; 17(4): 1318.

[21] Hewlett B. Relationships between hip range of motion, sprint kinematics and kinetics in track and field athletes. A thesis submitted to Auckland University of Technology in partial fulfillment of the requirements for the degree of Master of Sport and Exercise (MSpEx). 2013; 1-40. 
[2r] Folland JP, Allen SJ, Black MI, Handsaker JC, Forrester SE. Running Technique is an Important Component of Running Economy and Performance. Journal of Medicine \& Science in Sports \& Exercise 2017; 49(7): 1412-23.

[2ץ] Makaruk B, Makaruk H. Changes to flexibility of the hamstring in sprinters in the context of prevention. Polish Journal of Sport and Tourism 2009; 16(3):1524.

$[2 \uparrow]$ Ansari NW, Paul Y. Sharma K. Kinematic analysis of competitive sprinting. African Journal for Physical, Health Education, Recreation and Dance 2012; 18(4): 662-71.

[2ه] Inal HS, Erbug B, Kotzamanidis C. Sprinting, isokinetic strength, and range of motion of ankle joints in Turkish male and female national sprinters may have a relationship. Turk J Med Sci 2012; 42 (6): 1098-104.

[26] Pourrahim Ghouroghchi A, Pahlevani M. The Investigation of Relationship Between the Range of Motion Joints and Time of 50, 100 and $200 \mathrm{~m}$ Breaststroke Swimming in 12-13 years Elite
Swimmer Boys Participated in the National Championship of the Country Selection in $r \cdot 19$ year in Tehran. Journal of Practical Studies of Biosciences in Sport 2019; 18(2): 161-76. [Farsi]

[27] Bayat MR, Kalhor A, Shadmehr B, Soghadi J, Ebrahimi Atri A. Track and field. Samt 20ı0; 103-8.

[28] Vernillo G, Giandolini M, Edwards WB, Morin JB, Samozino P, Horvais N, Millet GY. Biomechanics and Physiology of Uphill and Downhill Running. Sports Med 2017; 47(1): 615-29.

[29] Scarfe AC. From theoty to practice: running kinematics of triathletes. A thesis submitted to The University of Birmingham for the degree of Doctor of Philosophy 2011; 32-84.

[30] Christopher SM, McCullough J, Snodgrass SJ, Cook C. Do alterations in muscle strength, flexibility, range of motion, and alignment predict lower extremity injury in runners: a systematic review. Archives of Physiotherapy 2019; 9(2): 1-14.

[31] USA, track and field (USATF). Track and field coaching essentials paperback. Human kinetics 2014; 20-300. 


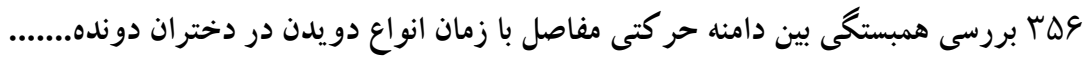

\title{
Investigating the Correlation between Range of Motion of Joints with the Time of Running Types in Adolescent Elite Runner Girls Participating in National Competitions in 2018 in Ardabil City: A Descriptive Study
}

\author{
$\underline{\text { A. PourRahim Ghouroghchi', M. Pahlevani', F. Akbari }}{ }^{r}$
}

Received: 05/02/2020 Sent for Revision: 08/05/2020 Received Revised Manuscript: 09/06/2020 Accepted: 15/06/2020

Background and Objectives: The relationship between range of motion of joints with running time is important to achieve athletic success. The aim of this study was investigating the correlation between range of motion of joints with the time of running types in adolescent elite runner girls participating in 2018 national competitions in Ardabil city.

Materials and Methods: In this descriptive study, subjects were 122 elite runner girls, 14-16 year, participated in the national championship of the country selection. Range of motion of joints was measured by Rydkov questionnaire. Pearson's correlation coefficient was used to examine the correlation between variables.

Results: There was a positive significant correlation between elbow flexion $(r=0.407, p=0.048)$ and $60 \mathrm{~m}$ hurdle running time, between hip hyperadduction $(\mathrm{r}=0.531, \mathrm{p}=0.005)$ and $400 \mathrm{~m}$ running time, trunk flexion ( $\mathrm{r}=0.656$, $\mathrm{p}=0.001)$ and $800 \mathrm{~m}$ running time, neck extension $(\mathrm{r}=0.646, \mathrm{p}=0.001)$ and neck lateral bending to left ( $\mathrm{r}=0.563$, $\mathrm{p}=0.006)$ and $3000 \mathrm{~m}$ running time, trunk lateral bending to right $(\mathrm{r}=0.418, \mathrm{p}=0.028)$, trunk lateral bending to left $(\mathrm{r}=0.382, \mathrm{p}=0.045)$, shoulder abduction $(\mathrm{r}=0.379, \mathrm{p}=0.047)$ and hip hyperextension $(\mathrm{r}=0.398, \mathrm{p}=0.038)$ and $4 \times 100 \mathrm{~m}$ relay race time. Whereas, there was a negative significant correlation between ankle dorsi flexion $(\mathrm{r}=-0.464$, $\mathrm{p}=0.022)$ and $60 \mathrm{~m}$ hurdle running time, between ankle inversion $(\mathrm{r}=-0.442, \mathrm{p}=0.030)$ and $800 \mathrm{~m}$ running time, shoulder hyperextension $(\mathrm{r}=-0.473, \mathrm{p}=0.017)$ and $1500 \mathrm{~m}$ running time, and ankle eversion $(\mathrm{r}=-0.440, \mathrm{p}=0.040)$ and $3000 \mathrm{~m}$ running time.

Conclusion: It seems that there is a significant correlation between the range of motion of joints and running time in elite runner girls. So, it is suggested that coaches pay attention to the results of this study for getting more success in reaching the peak of athletic performance.

Key words: Biomechanical characteristics, Running time, Girls, Elite runner, Ardabil

Funding: This study did not have any funds.

Conflict of interest: None declared.

Ethical approval: The Ethics Committee of Medical University of Adabil approved the study (IR.ARUMS.REC.1398.185).

How to cite this article: PourRahim Ghouroghchi A, Pahlevani M, Akbari F. Investigating the Correlation Between Range of Motion of Joints with the Time of Running Types in Adolescent Elite Runner Girls Participating in National Competitions in 2018 in Ardabil City: A Descriptive Study. J Rafsanjan Univ Med Sci 2020; 19(4): 341-56. [Farsi]

\footnotetext{
1- Assistant Prof. of Sport Physiology, Dept. of Physical Education and Sport Sciences, Faculty of Educational Sciences and Psychology, University of Mohaghegh Ardabili, Ardabil, Iran, ORCID: 0000-0003-3448-5950

(Corresponding Author) Tel: (045) 31505467, Fax: (045) 33520457, E-mail: amenehpoorrahim@yahoo.com

2- PhD Student of Sport Physiology, Dept. of Physical Education and Sport Sciences, Islamic Azad University, Sarab Branch, Sarab, Iran, ORCID: 0000-0003-4206-278X

3- BSc Student, Dept. of Physical Education and Sport Sciences, Faculty of Educational Sciences and Psychology, University of Mohaghegh Ardabili, Ardabil, Iran, ORCID: 0000-0001-72234314
}

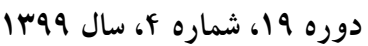

مجله دانشگاه علوم يزشكى رفسنجان 